\title{
Synthesis, characterization and application of magnetic carbon materials as electron shuttles for the biological and chemical reduction of the azo dye Acid Orange 10
}

\author{
L. Pereira ${ }^{a}{ }^{*}$, P. Dias ${ }^{a}$, O.S.G.P. Soares ${ }^{b}$, P.S.F. Ramalho ${ }^{b}$, M.F.R. Pereira $^{b}$, M.M. Alves $^{a}$ \\ ${ }^{a}$ CEB - Centre of Biological Engineering, University of Minho, 4710-057 Braga, Portugal \\ ${ }^{\mathrm{b}}$ Laboratório de Catálise e Materiais (LCM), Laboratório Associado LSRE-LCM, Departamento de Engenharia Química, Faculdade de Engenharia, \\ Universidade do Porto, Portugal
}

\section{A R T I C L E I N F O}

\section{Article history:}

Received 12 February 2017

Received in revised form 14 April 2017

Accepted 22 April 2017

Available online 25 April 2017

\section{Keywords:}

Azo dye reduction

Core-shell composites

Electron shuttle

Magnetic carbon materials

Redox mediators

\begin{abstract}
A B S T R A C T
A set of core(ferrite, FeO)-shell(carbon, C) composites, C@FeO, C@MnFeO, C@CoFeO, and carbon nanotubes (CNT) impregnated with $2 \%$ of Fe (CNT@2\%Fe) were prepared. The different composites were tested as redox mediators (RM) in the biological reduction of the azo dye Acid Orange 10 (AO10). Materials were tested at different concentrations from 0.1 to $1.0 \mathrm{~g} \mathrm{~L}^{-1}$. In the absence of RM, the AO10 decolourisation after $24 \mathrm{~h}$ of reaction was only $30 \%$ at a rate of $0.2 \mathrm{~d}^{-1}$. In the presence of the core-shell composites, better results were obtained with C@FeO materials at the amount of $1.0 \mathrm{~g} \mathrm{~L}^{-1}$. The extent of AO10 decolourisation was above $90 \%$ and rate improved circa 29 -fold. With CNT@2\%Fe, the best efficiency $(98 \pm 3 \%)$ was achieved with $0.5 \mathrm{~g} \mathrm{~L}^{-1}$ leading to a 79 -fold rate increase. In abiotic controls, though at lower extent, the reduction of the dyes also occurred likely due to the electron transfer from $\mathrm{Fe}^{2+}$ to carbon and then to the dye. To prove this, assays combining single CNT and $\mathrm{FeO}$ materials were performed, and $\mathrm{FeO}$ had effect in the reaction only when combined with CNT. In the biological assay, the rate was the double and the percentage of decolourisation increased from $(88 \pm 6) \%$ to $(97 \pm 1) \%$, when both materials were present in solution as compared with results in the presence of CNT alone. Under abiotic conditions, decolourisation occurred only in the presence of both materials, with a final percentage of $(54 \pm 2) \%$. Owing to their magnetic character, materials were removed from the media and successfully applied in successive cycles.
\end{abstract}

(C) 2017 Elsevier B.V. All rights reserved.

\section{Introduction}

Over the last few years, there has been an increased interest in studying magnetic nanoparticles (MNP), including iron magnetic oxides such as magnetite $\left(\mathrm{Fe}_{3} \mathrm{O}_{4}\right)$, hematite $\left(\alpha-\mathrm{Fe}_{2} \mathrm{O}_{3}\right)$, maghemite $\left(\gamma-\mathrm{Fe}_{2} \mathrm{O}_{3}\right)$ and nanoscaled zero-valent iron $\left(\mathrm{nFe}^{00}\right)$. The unique properties of MNP, such as high surface area, magnetic, sorption and catalytic characteristics, make them very versatile for many applications in different areas such as biomedicine/biotechnology, catalysis, magnetic sensors and magneto-optical devices [1]. MNP are also talented to be used in environmental remediation field as catalysts, adsorbents, immobilising agents for microorganisms and enzymes, and as supports for biofilm growth and water disinfectants $[2,3]$. In order to improve their stability and to intro-

\footnotetext{
* Corresponding author.

E-mail address: lucianapereira@deb.uminho.pt (L. Pereira).
}

duce additional surface properties and functionalities, MNP can be coated with a layer of different materials. CM are versatile coating materials due to their chemical stability, biocompatibility and possibility of tailoring their textural and surface chemical properties. CM are widely used as catalyst supports, but owing to their high specific surface area, pore volume distribution (micro, meso, macro), presence of diverse surface functional groups, good mechanical strength and the chance of being tailored for specific applications, their direct use as a catalyst is attracting interest [4]. The use of CM (eg. activated carbon, carbon xerogels, carbon nanotubes, carbon fibres and graphene) as redox mediators $(\mathrm{RM})$, accelerating the electron transfer and so the reduction rates, has been reported on decolourisation of dyes [5-11] and also on the reduction of nitrocompounds [12-16]. Compared to soluble $\mathrm{RM}$, insoluble materials such as CM have the advantage of being retained inside the reactors, avoiding the need to be fed continuously, and of being regenerated during the electron shuttling process, and thus being effective at low concentrations, decreasing 
the operating costs. Nevertheless, they need expensive techniques for their recovery and re-use. Magnetic separation is potentially a low cost, simple, quick and efficient way of separation. The combination of Carbon Materials with Magnetic Nanoparticles offers the possibility of creating magnetic carbon composites with synergistic properties: the adsorptive and catalytic properties of both and the magnetic character of MNP, improving the material performance and rendering it easier to be retained and recovered, by applying a magnetic field. Different C@MNP composites have been prepared by several researchers and applied on adsorption of contaminants. For instance, adsorption of chloroform, phenol, chlorobenzene and drimaren red dye, on magnetic AC was studied by Oliveira et al. [17]. Adsorption of different dyes onto magnetic composites has been described as well. As example, Ai et al. [18] have synthesized a composite of AC@CoFe $\mathrm{O}_{4}$ for the removal of malachite green dye from water.

Our investigation aims to prepare and characterize a set of magnetic CM composites (C@MNP) and applying them on the biological azo dye reduction, in batch assays. Materials include different coreshell composites, with a core composed of a ferrites of the type $\mathrm{FeO}$ and $\mathrm{MFeO}\left(\mathrm{M}\right.$, a divalent metal cation such as $\mathrm{Mn}^{2+}$ or $\mathrm{Co}^{2+}$ ) coated with carbon by chemical vapour deposition (CVD) or hydrothermal method (HdM) - C@MFeO, and CNT impregnated with $2 \%$ of Fe CNT@2\%Fe. As a model compound for the evaluation of the performance of the materials as RM, the azo dye AO10 was chosen, based on its recalcitrant nature as found in a previous study [8]. Azo dyes present in textile wastewaters have an enormous environmental impact being potential carcinogens. Therefore, their removal is a fundamental step in textile wastewater treatment. The proposed materials were removed from the media with a magnetic field and reused in successive cycles of dye reduction.

\section{Experimental}

\subsection{Chemicals}

$\mathrm{FeCl}_{3} \cdot 6 \mathrm{H}_{2} \mathrm{O}, \quad \mathrm{FeCl}_{2} \cdot 4 \mathrm{H}_{2} \mathrm{O}, \quad \mathrm{MnSO}_{4} \cdot \mathrm{H}_{2} \mathrm{O}, \quad \mathrm{Co}\left(\mathrm{NO}_{3}\right)_{2} \cdot 6 \mathrm{H}_{2} \mathrm{O}$, $\mathrm{Fe}\left(\mathrm{NO}_{3}\right)_{3}$, hydrochloric acid $(\mathrm{HCl}, 37 \%$, analytical grade), $\mathrm{NaOH}$, glucose and urea were purchased from Sigma-Aldrich. $\mathrm{C}_{2} \mathrm{H}_{6}, \mathrm{H}_{2}$, $\mathrm{N}_{2}$ and $\mathrm{NH}_{3}$ were purchased from Air liquid.

AO10 (dye content 90\%) was purchased from Sigma and used without additional purification. Stock solutions of $25 \mathrm{mM}$ were prepared in deionized water. The chemicals used to prepare the macronutrients solution were purchase from Sigma and acetonitrile (ACN) from Fluka at the highest analytic grade purity commercially available.

All chemicals were used as received and without further purification.

\subsection{Preparation of C@MNP}

A set of core(ferrite)-shell(carbon) nanocomposites, C@FeO, was prepared. The ferrites were firstly synthesized and then coated with carbon by the CVD process. One sample was also prepared by the HdM method. FeO nanoparticles were prepared by co-precipitation, according to Pereira et al. [19], $40 \mathrm{mmol}$ of $\mathrm{FeCl}_{3} \cdot 6 \mathrm{H}_{2} \mathrm{O}$ and $20 \mathrm{mmol}$ of $\mathrm{FeCl}_{2} \cdot 4 \mathrm{H}_{2} \mathrm{O}$ were dissolved in $50 \mathrm{~mL}$ of $2 \mathrm{M} \mathrm{HCl}$ solution. This solution was quickly added to $500 \mathrm{~mL}$ of $1.5 \mathrm{M} \mathrm{NaOH}$ solution at room temperature with vigorous mechanical stirring. A black precipitate formed immediately, and stirring was continued for $2 \mathrm{~h}$. Synthesis of $\mathrm{MnFeO}$ and $\mathrm{CoFeO}$ nanoparticles were made also by precipitation, according to Pereira et al. [1]. For $\mathrm{MnFeO}, 20 \mathrm{mmol}$ of $\mathrm{MnSO}_{4} \cdot \mathrm{H}_{2} \mathrm{O}$ were dissolved in $10 \mathrm{~mL}$ of $0.5 \mathrm{M} \mathrm{HCl}$ and $40 \mathrm{mmol}$ of $\mathrm{FeCl}_{3} \cdot 6 \mathrm{H}_{2} \mathrm{O}$ was dissolved in $80 \mathrm{~mL}$ of distilled water. The two solutions were heated at $50^{\circ} \mathrm{C}$, mixed and then quickly added to $400 \mathrm{~mL}$ of $3 \mathrm{M} \mathrm{NaOH}$ solution at $100^{\circ} \mathrm{C}$ with vigorous mechanical stirring. For $\mathrm{CoFeO}$, $20 \mathrm{mmol}$ of $\mathrm{Co}\left(\mathrm{NO}_{3}\right)_{2} \cdot 6 \mathrm{H}_{2} \mathrm{O}$ were dissolved in $10 \mathrm{~mL}$ of $0.5 \mathrm{M} \mathrm{HCl}$ and $40 \mathrm{mmol}$ of $\mathrm{FeCl}_{3} \cdot 6 \mathrm{H}_{2} \mathrm{O}$ were dissolved in $80 \mathrm{~mL}$ of distilled water. The two solutions were heated at $50^{\circ} \mathrm{C}$, mixed and then quickly added to $400 \mathrm{~mL}$ of $3 \mathrm{M} \mathrm{NaOH}$ solution at $100^{\circ} \mathrm{C}$ with vigorous mechanical stirring. In both cases, $\mathrm{MnFeO}$ and $\mathrm{CoFeO}$, a black precipitate was immediately formed, and stirring was continued for $2 \mathrm{~h}$ at $100^{\circ} \mathrm{C}$. After that time, the reaction mixtures were cooled to room temperature and the precipitates were magnetically separated and washed several times with distilled water. After the synthesis, the obtained MNP samples were coated with carbon by CVD (adapted from [20]). Firstly, the MNP were heated $\left(5^{\circ} \mathrm{C} \mathrm{min}^{-1}\right)$ in a nitrogen flow up to $400^{\circ} \mathrm{C}$ and then, the reduction was carried out in a hydrogen atmosphere for $2 \mathrm{~h}$. After that, the temperature was increased at $5^{\circ} \mathrm{C} \mathrm{min}-1$ up to $750{ }^{\circ} \mathrm{C}$ (samples C@FeO_CVD750,C@MnFeO_CVD750 and C@CoFeO_CVD750) or $850{ }^{\circ} \mathrm{C}$ (samples C@FeO_CVD850) to coat the MNP samples with carbon using ethane as carbon precursor. In other set of samples, ammonia was also applied with the aim to obtain CM doped with nitrogen (C@FeO_CVD750. $\mathrm{NH}_{3}$, C@MnFeO_CVD750. $\mathrm{NH}_{3}$, C@CoFeO_CVD750. $\mathrm{NH}_{3}$ and C@FeO_CVD $\left.850 \cdot \mathrm{NH}_{3}\right)$. For that $45 \mathrm{~cm}^{3} \mathrm{~min}^{-1}$ of either $\mathrm{C}_{2} \mathrm{H}_{6}: \mathrm{H}_{2}(25: 10)$ or $\mathrm{C}_{2} \mathrm{H}_{6}: \mathrm{NH}_{3}(20: 10)$ gas mixture was introduced at 750 or $850{ }^{\circ} \mathrm{C}$ during $2 \mathrm{~h}$. Then, the C@MNP were cooled under nitrogen flow until room temperature. Synthesis by the HdM method (sample C@FeO_HdM) was made according to Shouhu et al. [21]: $0.0015 \mathrm{~mol}$ of glucose, $0.009 \mathrm{~mol}$ of $\mathrm{FeCl}_{3} \cdot 6 \mathrm{H}_{2} \mathrm{O}$ and $0.15 \mathrm{~mol}$ of urea were dissolved in $60 \mathrm{~mL}$ of water under vigorous stirring. After being stirred for $20 \mathrm{~min}$, the solution was transferred and sealed in a $100 \mathrm{~mL}$ Teflon-sealed autoclave. The autoclave was kept at $180^{\circ} \mathrm{C}$ for $16 \mathrm{~h}$ before been cooled naturally. The products were separated by magnet, and washed with distilled water and ethanol several times. Then the products were dried at $80^{\circ} \mathrm{C}$ in an oven under vacuum for $17.5 \mathrm{~h}$.

Commercial multi walled carbon nanotubes (CNT) (Nanocyl 3100 , with an average diameter of $9.5 \mathrm{~nm}$, an average length of $1.5 \mathrm{~mm}$ with carbon purity higher than 95\%) were also used as catalysts and as support of the metal phase (Fe). For that, $2 \% \mathrm{wt}$ Fe monometallic catalyst supported on the CNT was prepared by incipient wetness impregnation from aqueous solution of the corresponding metal salt $\left(\mathrm{Fe}\left(\mathrm{NO}_{3}\right)_{3}\right)$. After impregnation, the sample was dried at $100^{\circ} \mathrm{C}$ for $24 \mathrm{~h}$, heat treated under nitrogen flow at $400^{\circ} \mathrm{C}$ for $1 \mathrm{~h}$, and finally reduced at $400^{\circ} \mathrm{C}$ in hydrogen flow for $3 \mathrm{~h}$ (sample CNT@2\%Fe).

\subsection{Characterization of MNP and C@MNP materials}

The textural and chemical properties of the materials were characterized by $\mathrm{N}_{2}$ adsorption at $-196^{\circ} \mathrm{C}$, temperature programmed reduction (TPR), thermogravimetric analysis (TG), transmission electron microscopy (TEM) and x-ray diffraction (XRD).

\subsection{1. $\mathrm{N}_{2}$ adsorption isotherms at $-196^{\circ} \mathrm{C}$}

$\mathrm{N}_{2}$ adsorption-desorption isotherms at $-196^{\circ} \mathrm{C}$ were measured on a Quantachrome NOVA 4200e multi-station apparatus. The sample was degassed in vacuum for $3 \mathrm{~h}$ at $150^{\circ} \mathrm{C}$ before analysis. The BET specific surface area $\left(S_{\mathrm{BET}}\right)$ was calculated from the nitrogen adsorption data in the relative pressure range of $0.05-0.3$.

\subsubsection{Thermogravimetric analysis}

The equipment used to perform these analyses was a Netzsch STA 409 PC Luxx ${ }^{\circledR}$. The analyses were carried out under a helium flow, at a heating rate of $10^{\circ} \mathrm{C} \mathrm{min}^{-1}$ from 50 to $900^{\circ} \mathrm{C}$, using two isothermal steps at $900^{\circ} \mathrm{C}: 7 \mathrm{~min}$ under helium flow and $13 \mathrm{~min}$ under air flow. 


\subsubsection{Temperature programmed reduction}

The TPR analyses were performed using an AMI-200 (Altamira Instruments) equipment, the sample $(100 \mathrm{mg})$ was heated at $5{ }^{\circ} \mathrm{C} \mathrm{min}^{-1}$ until $700{ }^{\circ} \mathrm{C}$ under a flow with $5 \%(\mathrm{v} / \mathrm{v})$ of $\mathrm{H}_{2}$ diluted in $\mathrm{Ar}$ (total flow rate of $30 \mathrm{~cm}^{3} \mathrm{~min}^{-1}$ ). The $\mathrm{H}_{2}$ consumption was followed by a thermal conductivity detector (TCD).

\subsubsection{X-ray diffraction}

The structure and phase purity of the prepared materials were analysed by X-ray diffraction using a Philips X'Pert MPD diffractometer $(\mathrm{Cu}-\mathrm{Ka}=0.15406 \mathrm{~nm})$. The data were collected in the range of $2 \theta=20^{\circ}-80^{\circ}$. The Rietveld refinement was used to analyse the results.

\subsubsection{Transmission electron microscopy}

TEM micrographs were obtained using a LEO 906E microscope operating with an accelerating voltage of $120 \mathrm{kV}$.

\subsubsection{X-ray photoelectron spectroscopy}

XPS analyses were performed using a Kratos AXIS Ultra HSA, with VISION software for data acquisition and CASAXPS software for data analysis. The analysis was carried out with a monochromatic Al Ka X-ray source (1486.7 eV), operating at $15 \mathrm{kV}(90 \mathrm{~W})$, in FAT (Fixed Analyser Transmission) mode, with a pass energy of $40 \mathrm{eV}$ for ROI (region of interest) and $80 \mathrm{eV}$ for survey.

\subsection{Biological dye reduction}

The prepared materials, single MNP and CNT, C@MNP and CNT@2\%Fe composites, were tested as RM on azo dye reduction, with AO10 as model compound. Biological reduction of AO10 was conducted in $70 \mathrm{~mL}$ serum bottles, sealed with a butyl rubber stopper, containing $25 \mathrm{~mL}$ of buffered medium at a pH of $7.3 \pm 0.2$ with $\mathrm{NaHCO}_{3}\left(2.5 \mathrm{~g} \mathrm{~L}^{-1}\right)$. The primary electron donating substrate of the medium was composed of $2 \mathrm{~g} \mathrm{~L}^{-1}$ chemical oxygen demand (COD) of a $\mathrm{NaOH}$ neutralised VFA mixture, containing acetate, propionate and butyrate in a COD based ratio of $1: 10: 10$. Basal nutrients were $\left(\mathrm{g} \mathrm{L}^{-1}\right)$ : $\mathrm{NH}_{4} \mathrm{Cl}(2.8), \mathrm{CaCl}_{2}$ (0.06), $\mathrm{KH}_{2} \mathrm{PO}_{4}(2.5), \mathrm{MgSO}_{4} \cdot 7 \mathrm{H}_{2} \mathrm{O}$ (1.0). Anaerobic granular sludge, collected from an anaerobic internal circulation reactor of a brewery wastewater treatment plant, was the inoculum at a concentration of $2 \mathrm{~g} \mathrm{~L}^{-1}$ of volatile suspended solids (VSS). The prepared materials, single MNP and CNT, C@MNP and CNT@2\%Fe composites, were present at increasing concentrations of $0.1,0.5$ and $1.0 \mathrm{~g} \mathrm{~L}^{-1}$. Concentration of $0.1 \mathrm{~g} \mathrm{~L}^{-1}$ was chosen based on previous results with single $\mathrm{CM}[7,8]$. However, as the composite materials have lower specific area, higher concentrations were also tested. Samples doped with nitrogen were tested only at concentration of $1.0 \mathrm{~g} \mathrm{~L}^{-1}$ due to the best results obtained with corresponding undoped samples. The medium was flushed with $\mathrm{N}_{2} / \mathrm{CO}_{2}(80 \% / 20 \%)$ and incubated overnight at $37^{\circ} \mathrm{C}$ in a rotary shaker at $105 \mathrm{rpm}$. After the pre-incubation period, AO10 $\left(0.5 \mathrm{mmol} \mathrm{L}^{-1}\right)$ and VFAís $\left(2 \mathrm{~g} \mathrm{~L}^{-1}\right.$ of COD) were added with a syringe from the stock solution to the desired concentration. Controls include: biological assays without materials and abiotic assays in the presence of the materials. Sterile controls were also conducted by autoclaving the reaction media with biomass, biomass and materials and only materials or only A010. The materials reutilization was studied by testing the AO10 decolourisation in successive cycles. For that, the materials were recovered from the reaction medium with a magnet after each cycle, washed with deionised water by centrifugation and reutilized in a fresh A010 solution. The operation conditions were the same in all cycles. All experiments were prepared in triplicate.

\subsection{Analytical techniques}

Samples were withdrawn from the bioreactors overtime, centrifuged and diluted up to an absorbance of less than 1 , with a freshly solution of ascorbic acid $\left(200 \mathrm{mg} \mathrm{L}^{-1}\right)$ to prevent aromatic amines oxidation. AO10 decolourisation was followed by spectrophotometry, measuring the absorbance at the dye wavelength of maximum absorbance, $480 \mathrm{~nm}$, in a 96-well plate reader (ELISA BIO-TEK, Izasa). AO10 concentration was calculated with the molar extinction coefficient of the dye $\left(\varepsilon_{480 \mathrm{~nm}}=24.56 \mathrm{mmol} \mathrm{L}^{-1} \mathrm{~cm}^{-1}\right)$. Dye reduction was confirmed by high performance liquid chromatography (HPLC) in an Ultra HPLC (Shimadzu Nexera XZ) equipped with a diode array detector (SPD-M20A), autosampler (SIL-30AC), degassing (DGU-20A5R) and LC -30AD, and a Labsolutions software. A RP-18 endcapped Purospher Star column ( $250 \mathrm{~mm} \times 4 \mathrm{~mm}, 5 \mu \mathrm{m}$ particle size, from MERK, Germany) was used. Mobile phase was composed of two solvents: $10 \mathrm{mM}$ ammonium acetate solution and ACN. Compounds were eluted at a flow rate of $0.8 \mathrm{~mL} \mathrm{~min}^{-1}$ at $30^{\circ} \mathrm{C}$, with an increase from $0 \%$ to $95 \%$ of $\mathrm{ACN}$ over $25 \mathrm{~min}$ and followed by an isocratic gradient during $10 \mathrm{~min}$. Samples were monitored at $480 \mathrm{~nm}$, for dye, and at $230 \mathrm{~nm}$, for aromatic amines identification.

The recovered MNP and C@MNP materials were analysed by scanning electron microscopy (SEM). For that, biological and nonbiological samples were previously filtered through a $0.2 \mu \mathrm{m}$ sterile filter using a filtration system, and immerse in a $2.5 \%(\mathrm{v} / \mathrm{v})$ glutaraldehyde solution made in PBS medium, during $2 \mathrm{~h}$ (fixation step). Samples were then washed three times with PBS buffer, $15 \mathrm{~min}$ each, and dehydrate through a series of ethanol baths in increasing concentrations: 10, 25, 50, 75, 90 and 100\% (v/v), $20 \mathrm{~min}$ each. The last step, $100 \%$ ethanol, was repeated for 30 min (dehydration step). Samples were dried for a few days in a desiccator (drying step). SEM analysis were then made at "Serviços de Caracterização de Materials" (SEMAT) at UM, Guimarães. Briefly, morphological analyses were carried out in an Ultra-high resolution field emission gun scanning electron microscopy (FEG-SEM), NOVA 200 Nano SEM, FEI Company. Topographic images were performed with an acceleration voltage of $10 \mathrm{kV}$. Samples were covered with a thin film (30 nm) of Au-Pd (80-20 wt\%) using a high resolution sputter coater, 208HR Cressington Company, coupled to a MTM-20 Cressington high resolution thickness controller. Chemical analyses of samples (without any conductive film) were performed with the energy dispersive spectroscopy (EDS) technique, using an EDAX $\mathrm{Si}(\mathrm{Li})$ detector, at an acceleration voltage of $25 \mathrm{kV}$, using a low vacuum detector.

\section{Results and discussion}

\subsection{Characterization of MNP and C@MNP}

Termogravimetric analyses (TG) were carried out to estimate the amounts of metal and carbon present in all the samples. The thermograms (not shown) of the original MNP samples and of the samples coated with carbon by CVD reveal that the materials only with the metal oxides did not exhibit significant weight loss, being of about $7.5 \%$ for $\mathrm{FeO}$ and $\mathrm{CoFeO}$, and $12.2 \%$ for $\mathrm{MnFeO}$, which are in agreement with the literature [20]. Considering the coated materials (C@MNP), a sharp weight loss at higher temperatures was observed, which is due to the burning of the carbon deposited on the metal particles [22]. The C@FeO_HdM sample exhibits a significant total mass loss due to carbon burning, which was covering the metallic nanoparticles. The relative amount of carbon (corresponding to the volatiles plus the burned mass in the TG experiments) and metal (corresponding to the remaining inorganic mass in the TG experiments) obtained in the C@MNP materials is given in Table 1. 
All the materials prepared by CVD have carbon in their composition. The materials prepared by CVD with ethane and ammonia have a higher amount of carbon ( $34 \pm 2 \%$ ) than those prepared only with ethane $(24 \pm 7 \%)$. For sample C@FeO_CVD, 35\% of carbon deposit was obtained increasing the growth temperature to $850^{\circ} \mathrm{C}$. The C@FeO_HdM sample presents 39\% of carbon, which is consistent with the literature [22].

The textural characterization of all the samples is shown in Table 1. It was observed that the MNP materials have a BET surface area between 101 and $184 \mathrm{~m}^{2} \mathrm{~g}^{-1}$. After the synthesis, the MNP were heated up to $400{ }^{\circ} \mathrm{C}$ to carry out the metals reduction under hydrogen and, after that, the temperature was increased up to 750 or $850^{\circ} \mathrm{C}$ to coat the MNP with carbon (C@MNP). This step drastically reduces the BET surface area of the original MNP samples to values lower than $10 \mathrm{~m}^{2} / \mathrm{g}$. In fact, TEM micrographs of samples $\mathrm{FeO}$ and $\mathrm{FeO}$ after being calcined at $400^{\circ} \mathrm{C}$ (see Fig. 2a) and b), respectively) reveal that the metallic particles are not well defined small spheres for sample $\mathrm{FeO}$ (average diameter of $13 \mathrm{~nm}$ ), whereas they become well defined with a significant larger size after being calcined at $400^{\circ} \mathrm{C}$ (average diameter of $115 \mathrm{~nm}$ ); thus this change in the morphology should be the reason for the BET surface area decrease. Similar values were reported by Yang et al. [23] for this type of materials. The coating with carbon by CVD increases the surface of the materials, mainly due to the covering of the MNP with carbon. Therefore, the BET surface areas presented in Table 1 for C@MNP materials are the surface area of the grown carbon (determined by TG) on the MNP.

The sample prepared by the incipient wetness impregnation method (CNT@2\%Fe) presents the highest surface area. This sample was supported on carbon nanotubes (CNT) that are a mesoporous material with a surface are of $283 \mathrm{~m}^{2} / \mathrm{g}$ [24] and the impregnation with iron only slightly decreases the surface due to the low amount of metal loaded. Characterization of CNT used in this work is described in previous publications $[8,9,16]$.

The TPR profiles of the MNP materials before and after carbon coating by CVD are shown in Fig. 1. In the TPR profile of $\mathrm{FeO}$ material (Fig. 1a), the characteristic reduction peaks of the $\mathrm{Fe}_{2} \mathrm{O}_{3}$ can be seen: between 300 and $400^{\circ} \mathrm{C}$ ( 1 st peak) occurs the metal reduction to $\mathrm{Fe}_{3} \mathrm{O}_{4}$ and between 400 and $700{ }^{\circ} \mathrm{C}$ (2nd peak) there is a sequential reduction of $\mathrm{Fe}_{3} \mathrm{O}_{4}$ to $\mathrm{FeO}$ and $\mathrm{Fe}^{0}$ Tristão et al. [20]. After the coating with carbon by the CVD process, these 2 peaks were not observed, which could be due to their previous reduction during the heat treatment step at $750^{\circ} \mathrm{C}$ ( or $850^{\circ} \mathrm{C}$ ) under reductive atmosphere and to the encapsulation of the iron oxides by the deposition of carbon. In the case of $\mathrm{MnFeO}$ (Fig. 1b), the reduction process may be described as $\mathrm{MnFe}_{2} \mathrm{O}_{4} \rightarrow \mathrm{MnFe}_{2} \mathrm{O}_{4-\delta} \rightarrow \mathrm{MnO}-\mathrm{FeO} \rightarrow \alpha$-Fe. Thus, the reduction peak around $350^{\circ} \mathrm{C}$ tends to be low, while the peak between 400 and $600^{\circ} \mathrm{C}$ is higher. For the 3 rd peak, after $600^{\circ} \mathrm{C}$, the structure of $\mathrm{MnFe}_{2} \mathrm{O}_{4}$ is destroyed showing the formation of $\mathrm{Fe}_{2} \mathrm{O}_{3}$. Therefore, this type of material besides providing ferrite $\mathrm{MnFe}_{2} \mathrm{O}_{4}$,

Table 1

Textural characterization, and carbon and metal amount, obtained by TG.

\begin{tabular}{|c|c|c|c|}
\hline Sample & $\mathrm{S}_{\mathrm{BET}}{ }^{\mathrm{a}}\left(\mathrm{m}^{2} \mathrm{~g}^{-1}\right)$ & Carbon(\%) & Metal(\%) \\
\hline $\mathrm{FeO}$ & 154 & - & 98 \\
\hline C@FeO_HdM & 31 & 39 & 61 \\
\hline C@FeO_CVD750 & 63 & 16 & 84 \\
\hline C@FeO_CVD850 & 29 & 35 & 65 \\
\hline C@FeO_CVD750.NH & 29 & 34 & 66 \\
\hline $\mathrm{MnFeO}$ & 101 & - & 98 \\
\hline C@MnFeO_CVD750 & 45 & 22 & 78 \\
\hline C@MnFeO_CVD750·NH $\mathrm{NH}_{3}$ & 31 & 32 & 68 \\
\hline $\mathrm{CoFeO}$ & 184 & - & 96 \\
\hline C@CoFeO_CVD750 & 29 & 34 & 66 \\
\hline C@CoFeO_CVD750.NH ${ }_{3}$ & 38 & 36 & 74 \\
\hline CNT@2\%Fe & 266 & 98 & 2 \\
\hline
\end{tabular}

a $\mathrm{S}_{\mathrm{BET}}$ of these materials was calculated per gram of carbon (determined by $\mathrm{TG}$ ).
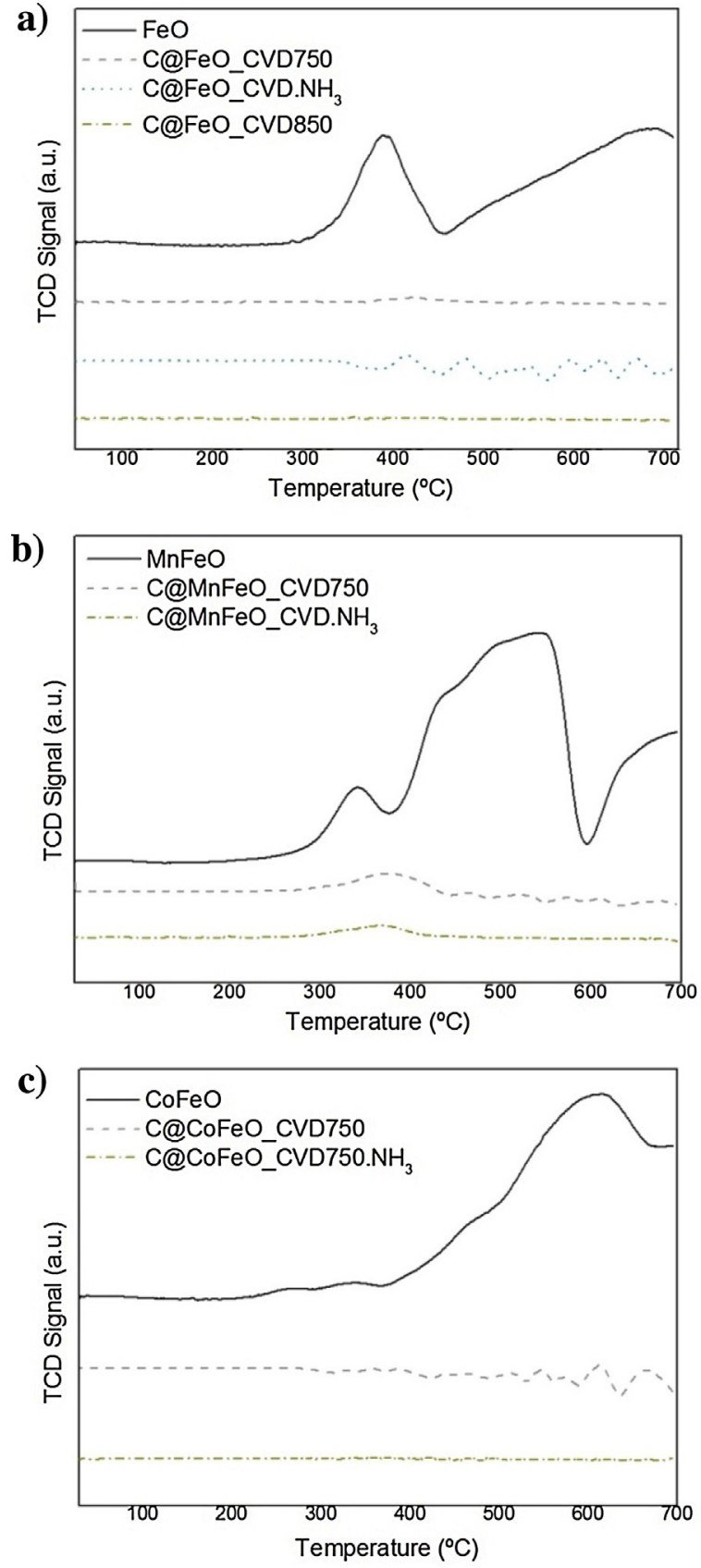

Fig. 1. TPR profiles of the a) FeO, b) Mn and c) Co MNP materials before and after carbon coating by CVD.

also shows the formation of $\mathrm{Fe}_{2} \mathrm{O}_{3}$ in its structure [25]. After the coating with carbon by the CVD method, these peaks were not observed, which can be explained by the same reasons presented above for the $\mathrm{FeO}$ sample. Cobalt reduction normally present two peaks, between 300 and $500{ }^{\circ} \mathrm{C}$, attributed to a two reduction steps of $\mathrm{Co}_{3} \mathrm{O}_{4}\left(\mathrm{Co}_{3} \mathrm{O}_{4} \rightarrow \mathrm{CoO} \rightarrow \mathrm{Co}^{00}\right)[23,26]$. The TPR profile of $\mathrm{CoFeO}$ (Fig. 1c) exhibits a large reduction peak with a maximum close to $600{ }^{\circ} \mathrm{C}$ related to the formation of magnetite $\left(\mathrm{Fe}_{3} \mathrm{O}_{4}\right)$ besides the reduction of $\mathrm{CO}_{3} \mathrm{O}_{4}$ to $\mathrm{Co}^{00}[23,27]$. As observed for the other MNP materials, after the coating with carbon by CVD the reduction peaks of the metals were not observed. The TPR profile of the C@FeO_HdM sample (result not shown) also does not present the characteristic peaks of the metal, which could indicate that the metals are covered by carbon. On the contrary, the TPR profile of the sample CNT@2\%Fe (result not shown) shows that the major reduction peak is located at 

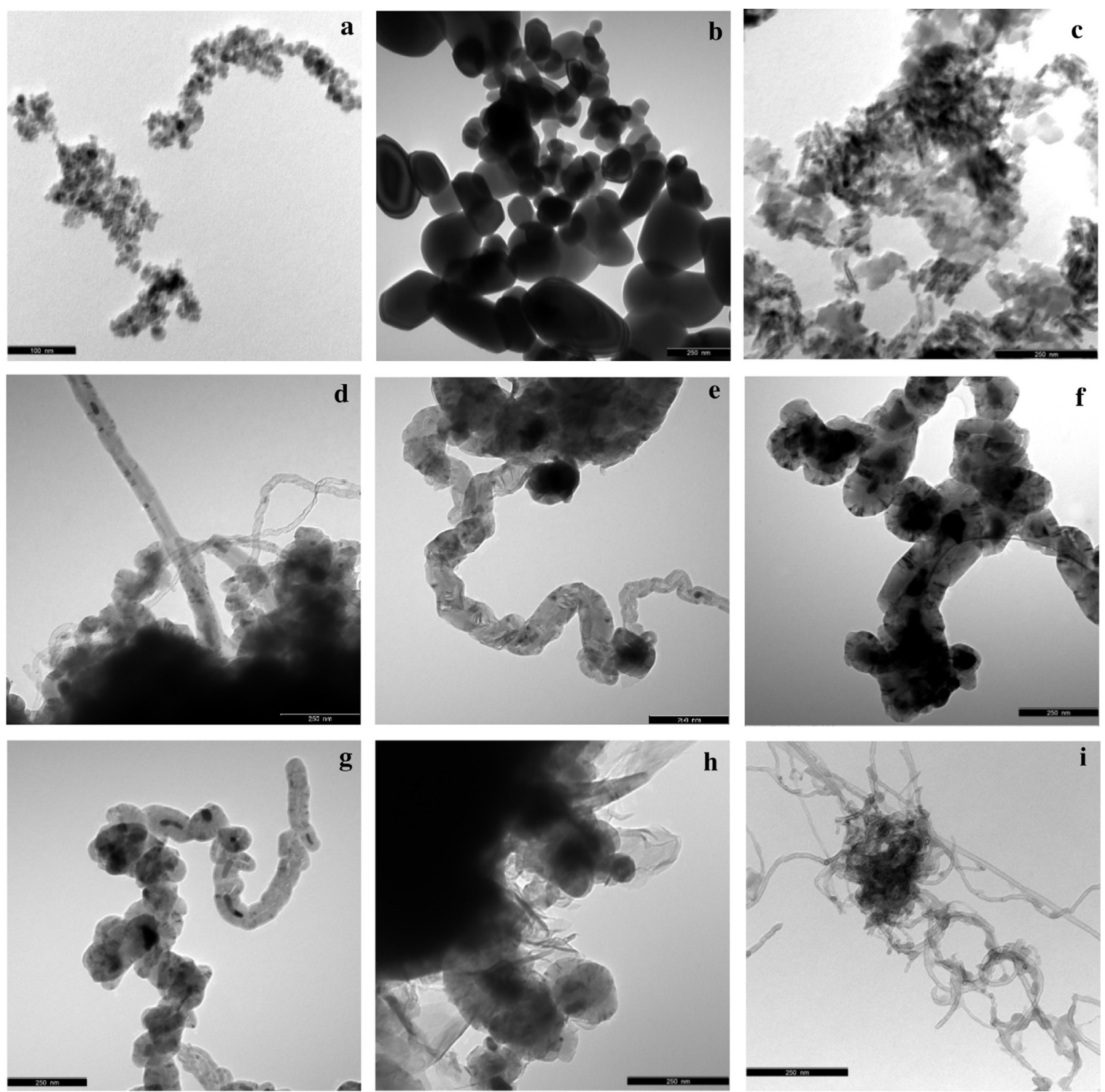

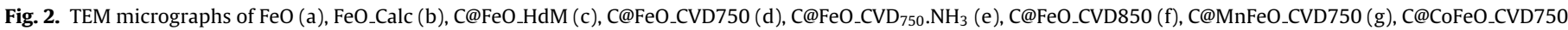
(h) and CNT@2\%Fe (i) materials.

a temperature around $380^{\circ} \mathrm{C}$; therefore, the temperature of $400{ }^{\circ} \mathrm{C}$ was selected to perform the reduction step, with hydrogen, of this sample to guarantee the complete reduction of the metal.

The XRD pattern of the FeO MNP (Fig. S1a, supplementary information (SI)) exhibits the characteristic peaks of iron oxides, confirming the expected cubic spinel structure (Fd3m) [19]. The enlargement of the diffraction peaks is attributed to the small size of the nanoparticles [28]. The diffractograms were adjusted using the Rietveld refinement in order to identify the nature of the materials. Table 2 shows the phases identified for the FeO MNP materials and the crystallite sizes. As expected [19], the FeO sample shows magnetite as main phase, whereas the C@MNP samples have a large amount of carbon in its composition, appearing as graphite with a percentage between 90 and $95 \%$.

The binding energies of the Fe 2p3/2 peak obtained by XPS analysis also revealed that sample $\mathrm{FeO}$ presents a large amount of iron in its composition ( $54.5 \% \mathrm{wt}$.), being this metal in the form of $\mathrm{Fe}^{2+}$ and $\mathrm{Fe}^{3+}$. In the case of the samples C@FeO_CVD750 and $\mathrm{C} @ \mathrm{FeO} \mathrm{CVD}_{750} \cdot \mathrm{NH}_{3}$ their surface is mainly composed by carbon, 96.7 and $96.5 \%$ (wt.\%) and only 0.37 and $0.60 \%$ of iron was detected, in both cases in the form of $\mathrm{Fe}^{2+}$ and $\mathrm{Fe}^{3+}$. These relative amounts are in agreement with the TPR results, indicating that the metals are encapsulated by the carbon. In the case of sample CNT@2\%Fe, although it had been reduced under hydrogen at $400{ }^{\circ} \mathrm{C}$ iron was found only in the form of $\mathrm{Fe}^{2+}$ and $\mathrm{Fe}^{3+}$. The nitrogen content in sample C@FeO_CVD $750 \cdot \mathrm{NH}_{3}$ is $0.3 \%$ (wt\%).

TEM micrographs were collected with the aim to obtain information about the structure of the carbon deposited on the MNP samples. Fig. 2 shows that all the samples prepared by CVD present carbon and that the preparation method has influence in the carbon structure. For the sample FeO (Fig. 2a) it can be seen that the metallic particles are small spheres not well defined, whereas after being calcined at $400^{\circ} \mathrm{C}$ (the calcination was carried out to evaluate the effect of the calcination step on the morphology of the material) it can be observed that the metal particles are well defined (sample FeO_Cal Fig. 2b) and present a significant larger size, which can be the reason for the drastic reduction of surface area (Table 1). Analysing the micrographs of sample C@FeO_HdM (Fig. 2c), it can be observed that the particles do not have carbon nanotubes or nanofibers in their structure, presenting an amorphous carbon form. For C@FeO_CVD750 sample (Fig. 2d), the metal is encapsulated, being coated by carbon nanotubes and nanofibers. 
Table 2

Properties of FeO and C@FeO_CVD materials obtained from XRD analysis.

\begin{tabular}{|c|c|c|c|}
\hline Sample & Phase (\%V/V) & Lattice parameter & Crystallite size \\
\hline $\mathrm{FeO}$ & Magnetite & $\mathrm{a}=8.3493$ & $\mathrm{tc}=20.5 \pm 0.5 \mathrm{~nm}$ \\
\hline \multirow[t]{3}{*}{ C@FeO_CVD750 } & Cementite $\left(\mathrm{Fe}_{3} \mathrm{C}\right)=2.99 \%$ & $\mathrm{Fe}_{3} \mathrm{C}(\mathrm{a}=5.0891 ; \mathrm{b}=6.7442 ; \mathrm{c}=4.5244)$ & Cementite $\left.\left(\mathrm{Fe}_{3} \mathrm{C}\right)=84 \pm 10 \mathrm{~nm}\right)$ \\
\hline & Fe $\alpha=1.59 \%$ & Fe $\alpha(\mathrm{a}=2.8672)$ & Fe $\alpha=72 \pm 5 \mathrm{~nm}$ \\
\hline & Graphite $=95.43 \%$ & Graphite $(\mathrm{a}=2.4527 ; \mathrm{c}=6.7607)$ & Graphite $=16 \pm 1 \mathrm{~nm}$ \\
\hline \multirow[t]{3}{*}{ C@FeO_CVD850 } & Cementite $\left(\mathrm{Fe}_{3} \mathrm{C}\right)=3.04 \%$ & $\mathrm{Fe}_{3} \mathrm{C}(\mathrm{a}=5.0902 ; \mathrm{b}=6.7514 ; \mathrm{c}=4.5258)$ & Cementite $\left.\left(\mathrm{Fe}_{3} \mathrm{C}\right)=52 \pm 10 \mathrm{~nm}\right)$ \\
\hline & Fe $\alpha=1.51 \%$ & Fe $\alpha(a=2.8682)$ & Fe $\alpha=73 \pm 5 \mathrm{~nm}$ \\
\hline & Graphite $=95.45 \%$ & Graphite $(\mathrm{a}=2.4585 ; \mathrm{c}=6.7382)$ & Graphite $=27 \pm 1 \mathrm{~nm}$ \\
\hline \multirow[t]{3}{*}{ C@FeO_CVD850·NH 3} & Cementite $\left(\mathrm{Fe}_{3} \mathrm{C}\right)=3.28 \%$ & $\mathrm{Fe}_{3} \mathrm{C}(\mathrm{a}=5.0879 ; \mathrm{b}=6.7414 ; \mathrm{c}=4.5245)$ & Cementite $\left.\left(\mathrm{Fe}_{3} \mathrm{C}\right)=15 \pm 5 \mathrm{~nm}\right)$ \\
\hline & Fe $\alpha=1.43 \%$ & Fe $\alpha(\mathrm{a}=2.8667)$ & Fe $\alpha=<130 \mathrm{~nm}$ \\
\hline & Graphite $=95.29 \%$ & Graphite $(\mathrm{a}=2.4549 ; \mathrm{c}=6.7408)$ & Graphite $=14 \pm 5 \mathrm{~nm}$ \\
\hline
\end{tabular}

The sample C@FeO_CVD750· $\mathrm{NH}_{3}$ (Fig. 2e) presents carbon nanotubes with bamboo-like structure due to the use of a nitrogen precursor during the carbon growth [29]. The increase of the temperature during the carbon growth step, sample C@FeO_CVD850 (Fig. 2f), increases the formation of carbon nanotubes and carbon nanofibers, which is in agreement with the TG analyses, since this sample presents a higher amount of carbon than sample C@FeO_CVD750. In the case of the sample MnFeO, the use of ethane alone (Fig. 2g - sample C@MnFeO_CVD750) or ethane and ammonia (image not shown), during the coating of the MNP with carbon, do not have a significant influence on the carbon structure formed. In all materials, it can be observed that the metal is encapsulated in the carbon nanotubes. On the contrary, CoFeO MNP samples are coated with different carbon structures:C@CoFeO_CVD750 (Fig. 2h) presents few carbon filaments and amorphous carbon coating the metals, whereas C@CoFeO_CVD750· $\mathrm{NH}_{3}$ (image not shown) also presents a carbon nanotube bamboo-like structure. Fig. $2 \mathrm{i}$ ) shows that iron is well dispersed on the commercial nanotubes (sample CNT@2\%Fe), this is mainly related to the low amount of metal used during the impregnation step.

\subsection{Biological decolourisation of AO10}

Decolourisation of A010 under biologic and abiotic conditions was followed over $24 \mathrm{~h}$, time at which the equilibrium was reached and no further decrease on AO10 concentration was observed (Figs. S2, SI). As can be observed in Fig. S2, the reactions followed first-order kinetics. The extent and rates of A010 decolourisation at the different conditions were calculated and the main results are set in Table 3 . In supplementary material, all the results are presented (Table $\mathrm{S} 1$ ). In the absence of materials, biological decolourisation was $\sim 30 \%$ at a rate of $\sim 0.2 \mathrm{~d}^{-1}$. Contrarily to the results obtained with single $\mathrm{CM}$ at concentration of $0.1 \mathrm{~g} \mathrm{~L}^{-1}$, that lead to a considerable increase of rates and extents of different azo dyes biological reduction [7,8], the presence of MNP and C@MNP core-shell materials at concentration of $0.1 \mathrm{~g} \mathrm{~L}^{-1}$ had no effect on the reaction, with exception of sample C@FeO_CVD850, which caused a slight increase in the extent and rates: $(36 \pm 8) \%$ at a rate of $(0.25 \pm 0.05) \mathrm{d}^{-1}$ (Table S1, SI). This is explained by the low $\mathrm{S}_{\mathrm{BET}}\left(<10 \mathrm{~m}^{2} \mathrm{~g}^{-1}\right)$ as compared with single CM (ex.: $1032 \mathrm{~m}^{2} \mathrm{~g}^{-1}$ for AC and $331 \mathrm{~m}^{2} \mathrm{~g}^{-1}$ for CNT, [7,8]). Indeed, when the concentration of C@MNP materials was increased to 0.5 or $1.0 \mathrm{~g} \mathrm{~L}^{-1}$, the extent and rates of AO10 biological decolourisation have also improved (Table 3 and S1,SI). The single MNP had no effect in the AO10 decolourisation at all the tested concentrations. Among the C@MNP core-shell materials tested, the best was the C@FeO_CVD850 composite: at concentration of $0.5 \mathrm{~g} \mathrm{~L}^{-1}$ the rate of AO10 biological decolourisation increased around 12-fold $(2.59 \pm 0.27) \mathrm{d}^{-1}$, reaching the extent of $70 \pm 1 \%$, and at $1.0 \mathrm{~g} \mathrm{~L}^{-1}$ rate increased 24 -fold $\left(4.94 \pm 0.40 \mathrm{~d}^{-1}\right)$ and the final removal was $(92 \pm 1) \%$. Sample prepared at $750^{\circ} \mathrm{C}\left(\mathrm{C} @ \mathrm{FeO} \_\mathrm{CVD} 750\right)$ was less efficient on A010 decolourisation probably due to the low amount of carbon on the material shell. The results with C@FeO_CVD.NH 3 were similar to the obtained with the C@FeO_CVD850 in terms of final A010 reduction, but the rate almost duplicated, indicating that the treatment with $\mathrm{NH}_{3}$ improves the catalyst performance of the material. For C@CoFeO750 and C@MnFeO750 materials, there was no effect of using ammonia in the synthesis, similar results were obtained among $\mathrm{N}$-doped and undoped materials. The doping of $\mathrm{CM}$ with heteroatoms (like $\mathrm{N}$ ) allows rearrange the electrons in the carbon surface and changes the electronic properties of the $\mathrm{CM}$, enhancing their stability and catalytic performance [4]. The amount of carbon in all materials was similar, and so the differences between them may not be related with that. In the case of sample prepared by the hydrothermal method, the amount of carbon is lower. Notwithstanding, the $\mathrm{pH}_{\mathrm{pzc}}$ is other factor that may contribute for the lower efficiency of C@FeO_HdM. Materials have amphoteric character and, as a result, their surfaces might be positively or negatively charged depending on the $\mathrm{pH}$ of the solution: the surface of materials becomes positively charged at $\mathrm{pH}<\mathrm{pH}_{\mathrm{pzc}}$ and negatively at $\mathrm{pH}>\mathrm{pH}_{\mathrm{pzc}}$. Since the tested dye is anionic, therefore negatively charged when in solution, adsorption and transfer of electrons are more favorable when the material's surface is positively charged. Negatively charged surface sites on the materials might cause the electrostatic repulsion of the anionic dye. With exception of sample prepared by the hydrothermal method, which has a $\mathrm{pH}_{\mathrm{pzc}}$ of 6.7 , all the composites have a $\mathrm{pH}_{\mathrm{pzc}}$ above 10 . Treatment with $\mathrm{NH}_{3}$ includes $\mathrm{N}$ groups in the carbon shell, which confer basic character and high electronic mobility. As the reaction occurs at pH 7, sample C@FeO_HdM is the less favorable for the reaction. Other factor to be considered is that carbon in C@FeO_HdM composite presents an amorphous form.

CNT impregnated with $2 \%$ of iron were also tested in $\mathrm{AO} 10$ decolourisation and good efficiency as RM was observed at all the tested concentrations, leading to almost complete dye decolourisation (Table 3 \& Table S1, SI). Rates of AO10 decolourisation were highly improved in the presence of CNT@2\%Fe, as compared with the control assay: 55-fold with $0.1 \mathrm{~g} \mathrm{~L}^{-1}, 79$-fold with $0.5 \mathrm{~g} \mathrm{~L}^{-1}$ and 66 -fold with $1.0 \mathrm{~g} \mathrm{~L}^{-1}$. A010 decolourisation in the presence of single CNT was previously reported [8]; however, the presence of iron nanoparticles increased the catalytic effect, probably by transferring electrons to CNT, as will be explained ahead in the proposed mechanism. The best performance obtained with CNT@2\%Fe may be due to the high carbon content and specific surface area.

\subsection{Abiotic reduction of $A O 10$}

In abiotic assays, in the presence of C@FeO_CVD750, C@FeO_CVD850, C@@FeO_CVD850·NH 3 , C@MnFeO_CVD750, C@MnFeO_CVD750.NH 3 and CNT@2\% Fe composites, AO10 decolourisation also occurred, with better results with $1.0 \mathrm{~g} \mathrm{~L}^{-1}$ of C@FeO_CVD850. $\mathrm{NH}_{3}$, among the core-shell materials, and $0.5 \mathrm{~g} \mathrm{~L}^{-1}$ of CNT@2\%Fe (Table 3 and table S1, SI). The extent and rate of AO10 decolourisation with $1.0 \mathrm{~g} \mathrm{~L}^{-1}$ of C@FeO_CVD850. $\mathrm{NH}_{3}$ 
Table 3

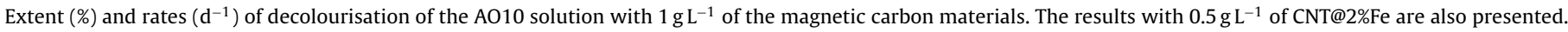
Controls include the assays with biomass (biotic) and with only AO10 (abiotic) without materials.

\begin{tabular}{|c|c|c|c|c|}
\hline \multirow[t]{2}{*}{ Samples } & \multicolumn{2}{|c|}{ Biotic assays } & \multicolumn{2}{|c|}{ Abiotic assays } \\
\hline & $\begin{array}{l}\text { Dec. } \\
(\%)\end{array}$ & $\begin{array}{l}\text { Rate } \\
\left(\mathrm{d}^{-1}\right)\end{array}$ & $\begin{array}{l}\text { Dec. } \\
(\%)\end{array}$ & $\begin{array}{l}\text { Rate } \\
\left(d^{-1}\right)\end{array}$ \\
\hline Control & $31 \pm 3$ & $0.21 \pm 0.03$ & 0 & 0 \\
\hline Control sterile & 0 & 0 & 0 & 0 \\
\hline $\mathrm{FeO}$ & $26 \pm 6$ & $0.15 \pm 0.03$ & 0 & 0 \\
\hline $\mathrm{CoFeO}$ & $31 \pm 5$ & $0.19 \pm 0.03$ & 0 & 0 \\
\hline $\mathrm{MnFeO}$ & $25 \pm 5$ & $0.15 \pm 0.03$ & 0 & 0 \\
\hline C@FeO_HdM & $24 \pm 4$ & $0.14 \pm 0.01$ & 0 & 0 \\
\hline C@FeO_CVD750 & $79 \pm 1$ & $0.13 \pm 2.11$ & \pm 439 & $0.11 \pm 0.41$ \\
\hline C@FeO_CVD850 & $92 \pm 1$ & $4.94 \pm 0.40$ & $80 \pm 8$ & $3.45 \pm 0.20$ \\
\hline C@FeO_CVD850 sterile & $67 \pm 6$ & $3.75 \pm 1.01$ & $62 \pm 4$ & $2.87 \pm 0.31$ \\
\hline C@FeO_CVD750·NH 3 & $93 \pm 1$ & $6.15 \pm 0.37$ & $94 \pm 2$ & $4.70 \pm 0.63$ \\
\hline C@CoFeO_CVD750 & $87 \pm 2$ & $2.69 \pm 0.27$ & 0 & 0 \\
\hline C@CoFeO_CVD750·NH $\mathrm{NH}_{3}$ & $91 \pm 3$ & $2.68 \pm 0.06$ & 0 & 0 \\
\hline C@MnFeO_CVD750 & $84 \pm 6$ & $3.33 \pm 1.39$ & $37 \pm 3$ & $0.62 \pm 1.49$ \\
\hline C@MnFeO_CVD750·NH 3 & $82 \pm 7$ & $3.67 \pm 0.02$ & $59 \pm 11$ & $3.70 \pm 0.23$ \\
\hline CNT@2\%Fe $\left(1 \mathrm{~g} \mathrm{~L}^{-1}\right)$ & $95 \pm 1$ & $13.93 \pm 2.94$ & $96 \pm 1$ & $10.25 \pm 1.77$ \\
\hline CNT@2\%Fe $\left(0.5 \mathrm{~g} \mathrm{~L}^{-1}\right)$ & $98 \pm 3$ & $16.66 \pm 2.00$ & $92 \pm 1$ & $13.09 \pm 1.10$ \\
\hline
\end{tabular}

$\mathbf{a}$

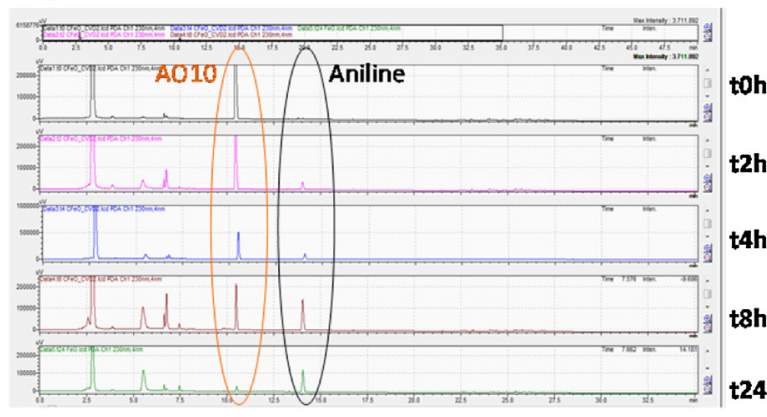

c

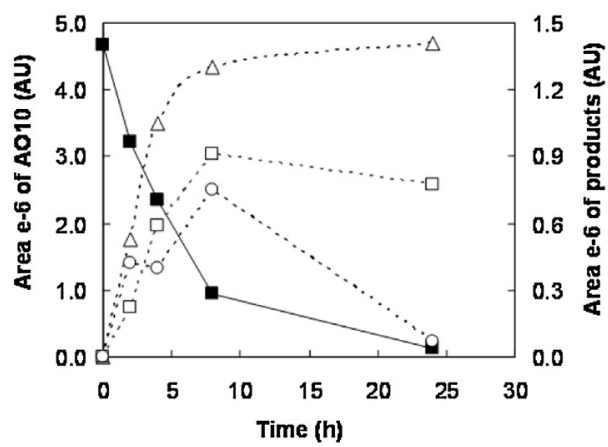

b
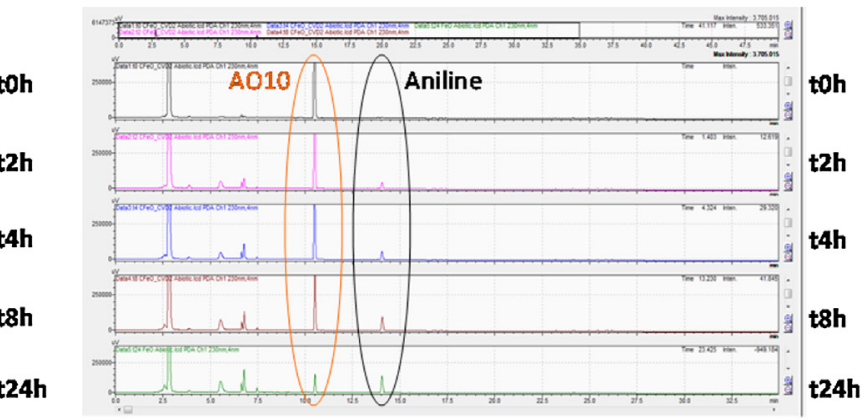

d

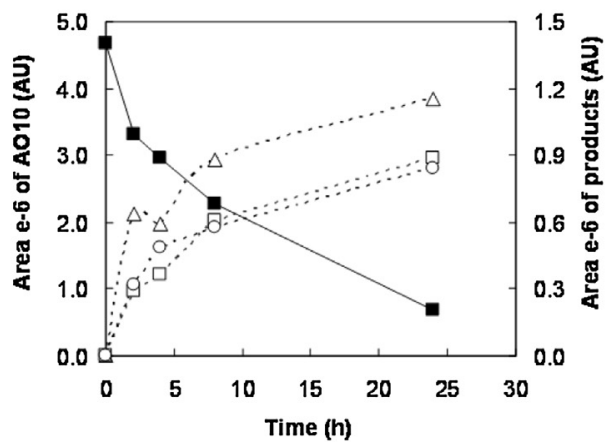

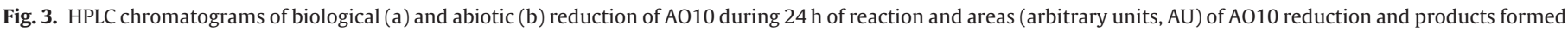

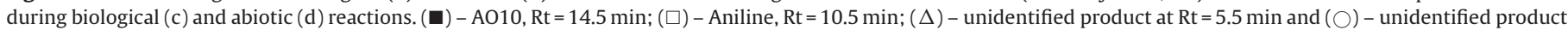
at $\mathrm{Rt}=6.8 \mathrm{~min}$.

in the abiotic experiment was $(94 \pm 2) \%$ and $(4.70 \pm 0.63) \mathrm{d}^{-1}$, respectively, and with $0.5 \mathrm{~g} \mathrm{~L}^{-1} \mathrm{CNT} @ 2 \% \mathrm{Fe}$ were $(92 \pm 1) \%$ and $(13.09 \pm 1.10) \mathrm{d}^{-1}$, respectively (Table 3 and Table S1, SI). A control with sterile C@FeO_CVD850 material was also conducted and, in the case of abiotic process, the result was similar in sterile and non-sterile conditions, proving that the reduction of dye in abiotic reactors was not a biological process by a possible microbial contamination. Moreover, HPLC analysis confirmed that the AO10 decolourisation in biotic and abiotic experiments was due to azo dye reduction and not to adsorption on materials (Fig. 3). As can be seen, the chromatogram peak corresponding to A010 at retention time (Rt) of 10.5 min decrease over reaction time and new peaks, corresponding to products of reaction, increase. As compared with the standard, one of the products (Rt of $14.5 \mathrm{~min}$ ) was assigned as aniline, confirming the reduction of the dye in bio and abiotic assays.

Based in these results, the presence of iron nanoparticles seems to have an effect also on the catalysis. So, batch reactors for the decolourisation of AO10 were operated with the mixture of single CNT, at a concentration of $0.1 \mathrm{~g} \mathrm{~L}^{-1}$, and $\mathrm{FeO}$, at concentrations of $0.1,0.5$ and $1.0 \mathrm{~g} \mathrm{~L}^{-1}$. The extents and rates of AO10 decolourisation under biological and abiotic conditions are set in Table S2 (SI). As expected, the presence of CNT increased the extent and rate of AO10 decolourisation under biological conditions. However, in abiotic reactors with CNT, decolourisation occurred only when $\mathrm{FeO}$ nanoparticles were present. Moreover, the presence of $\mathrm{FeO}$ 
nanoparticles improved decolourisation in biological reactors, as well, and the higher extent and rate of decolourisation were found when the materials were present at similar concentration, $0.1 \mathrm{~g} \mathrm{~L}^{-1}$. Mass transfer problems and competition when $\mathrm{FeO}$ nanoparticles were at higher amount may be the limitation. The results here obtained evidence the role of $\mathrm{FeO}$ nanoparticles not only given the magnetic character to the materials, but also as catalysts, participating in the electron shuttling.

\subsection{Mechanism of A010 reduction}

According to the results, a mechanism for the A010 reduction catalyzed by C@FeO composites is proposed (Fig. 4). In biological assays, electrons transfer may occur through: 1) the biological oxidation of the co-substrate (VFA) to the final acceptor, AO10;2) the biological oxidation of the co-substrate (VFA) to carbon shell (in core-shell composites) or CNT of the composites and then to the final acceptor, $\mathrm{AO} 10 ; 3)$ from $\mathrm{FeO}\left(\mathrm{Fe}^{2+}\right)$ of the core of composite to carbon shell (in core-shell composites) or the $\mathrm{Fe}\left(\mathrm{Fe}^{2+}\right)$ impregnated in CNT to the carbon of the composites and then to the final acceptor, A010. In the case of abiotic process, only the third mechanism of electron transfer may occur, from $\mathrm{FeO}\left(\mathrm{Fe}^{2+}\right)$ to the carbon of the composite and then to the final acceptor.

It is worthnoting that samples FeO, C@FeO_CVD750, C@FeO_CVD $750 \cdot \mathrm{NH}_{3}$ and CNT@2\%Fe were analysed by XPS and through the analysis of the $2 \mathrm{p} 3 / 2$ spectrum it was observed in all samples the presence of $\mathrm{Fe}^{2+}$ and $\mathrm{Fe}^{3+}$ independently of the preparation method. Although sample CNT@2\%Fe had been reduced under hydrogen at $400^{\circ} \mathrm{C}$ some surface oxidation could result from the contact with air during sample manipulation and due to that no ZVI iron was observed.

The adsorption and catalytic activity of iron oxides have been previously reported. These competences are substantiated by their high specific area and chemical activity, appealing for their application in the adsorption and degradation of many contaminants, largely toxic metals, but also dyes, chlorinated organics and other pollutants [30,31]. Direct electron transfer from nanoscaled $\mathrm{Fe}^{0}$ to contaminants has been described as an important pathway of con- taminant transformation [32-34]. For instance, Adebiyi et al. [35] have found that the addition of $4 \mathrm{mg} \mathrm{L}^{-1}$ of $\mathrm{nFe}^{0}$ could enhance 4 -fold the biodegradation of the azo dye Reactive Red 2 in a sulphidogenic bioreactor.

A tri-component composite of reduced graphene oxide (RGO), $\mathrm{Fe}_{3} \mathrm{O}_{4}$ and $\mathrm{Ag}$ NP ( $\mathrm{RGO@} \mathrm{Fe}_{3} \mathrm{O}_{4} / \mathrm{Ag}$ ) was applied by Ji et al. [36] on the chemical reduction of 4-nitrophenol into 4-aminophenol. The proposed composite showed a 3-fold higher catalytic activity than RGO@Ag, demonstrating that the presence of iron oxide had not only the function of conferring magnetic character to the composite, but also may participate in the electron transfer. However, contrarily to our results, in the absence of the catalytic $\mathrm{Ag}$ (composite $\mathrm{RGO} @ \mathrm{Fe}_{3} \mathrm{O}_{4}$ ) 4-nitrophenol was not reduced.

\subsection{Recycling materials on reduction of $A 010$}

The objective of preparing and applying the C@MNP composites as RM of biological reactions was to bring together the catalytic properties of CM and the magnetic character of MNP, rendering the catalyst easier to be retained and recovered, by the application of a magnetic field. In this view, the best materials, C@FeO_CVD850 and CNT@2\%Fe were tested in three successive cycles. To do this, at the end of the experiment, the materials were removed from the media and applied in successive cycles of AO10 decolourisation (Fig. 5). The results obtained in the control and also in biological assay in the presence of $\mathrm{FeO}$, indicate that the biomass activity was similar in all the reaction cycles, as the extents and rates were comparable. With the core-shell material, a decrease of circa $20 \%$ of AO10 decolourisation occurred during the biological cycles and rates decline was lower than 2-fold (Table S3, SI). In abiotic assays, the decrease was higher, $61 \%$ from 1 st to the 3rd cycle at a 5-fold lower rate. Sample CNT@2\%Fe was more effective during the successive cycles. After the 3rd cycle, the extent of A010 decolourisation with this material was similar and rate decreases only 1.8 -fold. However, in abiotic assays, this material has also lost some of the catalytic properties. The decrease on catalytic properties in the absence of biomass is expected, because under abiotic conditions, according to the proposed mechanism for AO10 reduc-

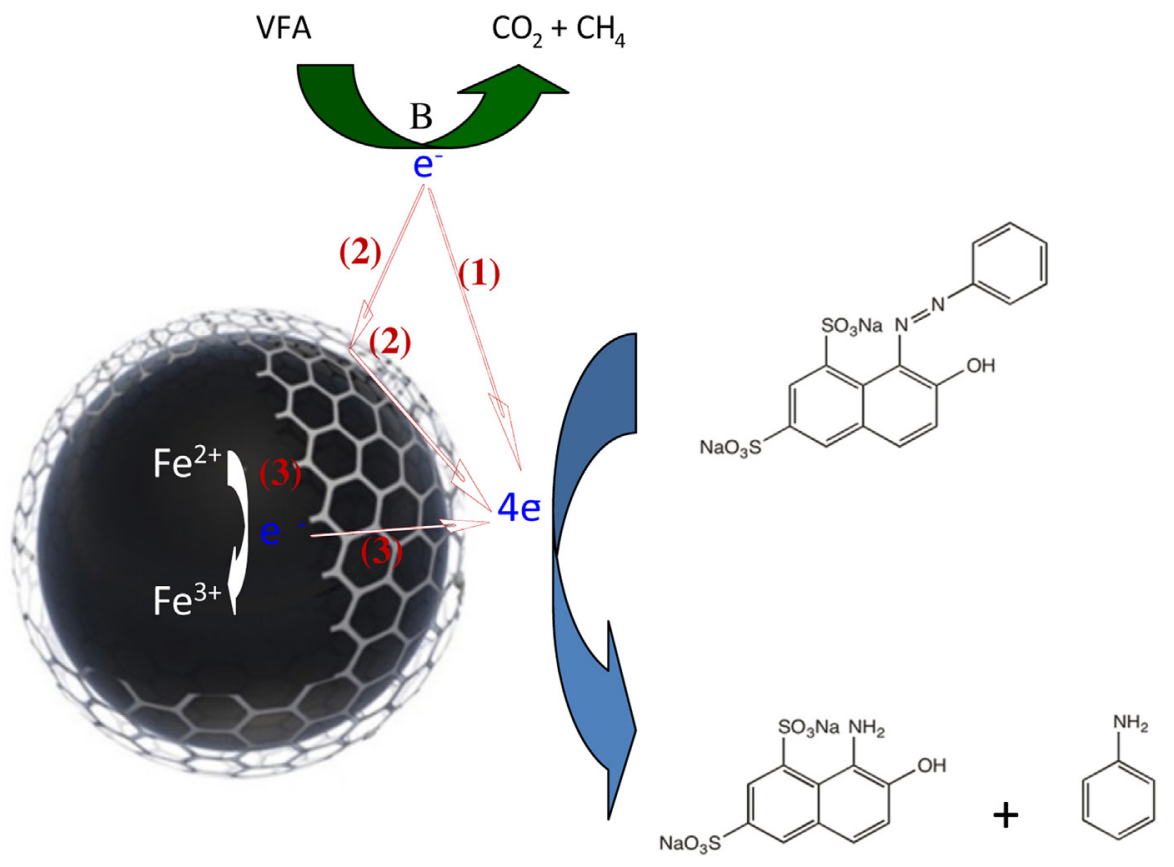

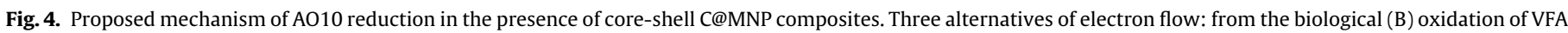
to $\mathrm{AO} 10$ (1) or to carbon shell of the composite and then to $\mathrm{AO10}(2)$ and from $\mathrm{Fe}^{2+}$ of the core to carbon shell of the composite and then to AO10 (3). 


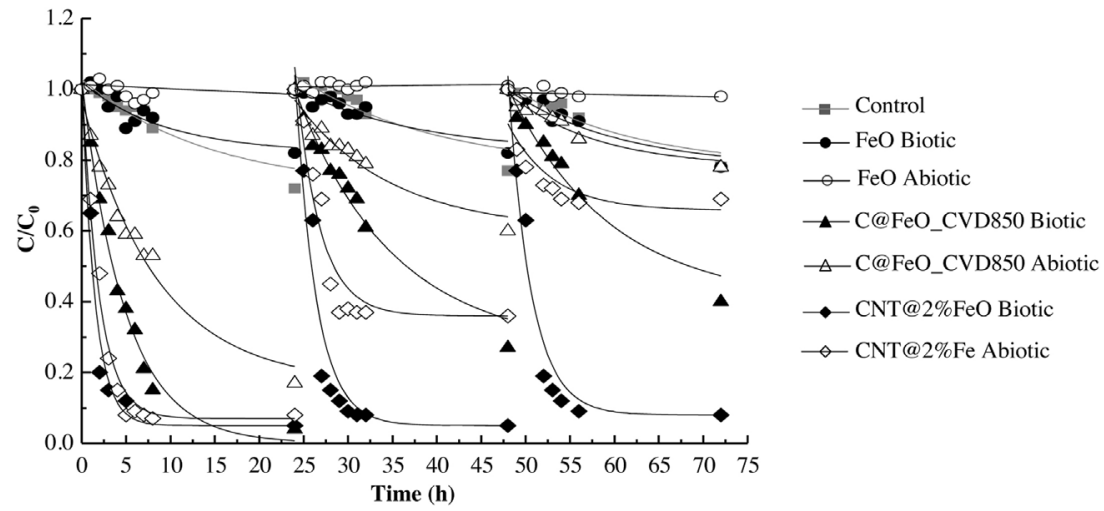

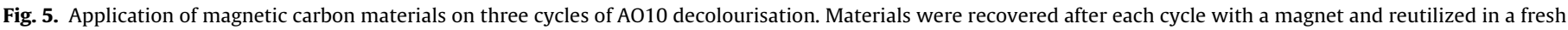
A010 solution.

tion, and consequently decolourisation, the electron transfer occurs from $\mathrm{Fe}^{2+}$ to carbon of the material and then to A010. Accordingly, decrease may be related to the fact that there are not more electrons available as the material is not regenerated as happens in the biological experiments. In biological assays, the catalyst is reversibly oxidised and reduced, by receiving electrons from the substrate (VFA) and transferring them to AO10, therefore maintaining the catalytic properties.

SEM analysis of sample C@FeO_CVD were carried out before (Fig. S3, A and B) and after the first and third cycles of biological (Fig. S4, A-C and D-F, respectively) and abiotic experiments (Fig. S4, G-I, respectively). The pristine composites were completed cover by carbon (Fig. S3B) and after the cycles of biological application, carbon shell of C@FeO_CVD was still present (Fig. S4, C-H). Interestingly, microorganisms of Sarcina type could be distinguished in the carbon film (Fig. S4, C \& F). Contrarily to the obtained in the biological experiments, thought their good performance as catalysts also under abiotic conditions, the core-shell materials have lost a main part of the carbon of the shell, present in the reactors as a carbon precipitate, after the third cycle which may explain the decrease on its performance (Fig. S4, I-K). In the experiments with CNT@2\%Fe, any carbon precipitate was obtained, indicating the better stability of the material, which have maintained the efficiency over the three cycles of application on biological AO10 reduction.

\section{Conclusions}

The application of low concentrations of magnetic carbon composites on the biological treatment of the azo dye AO10 solution increased the yields and rates of the reaction. When core-shell materials were applied, rate improvement up to 29-fold was obtained and with CNT impregnated with $2 \%$ of $\mathrm{Fe}$, rates were increased up to 79 times, as compared with the control in the absence of carbon materials. Moreover, CNT@2\%Fe was more effective at lower concentrations, 0.1 and $0.5 \mathrm{gL}^{-1}$, while core-shell materials had effect only at 0.5 and $1.0 \mathrm{~g} \mathrm{~L}^{-1}$. Catalytic effect was also observed in abiotic reactors in the presence of composites probably due to the transfer of electrons from nanoscale iron to carbon and then to the dye.C@FeO_CVD850 and CNT@2\%Fe were successfully applied in successive cycles of AO10 decolourisation. However, the core-shell materials have lost some efficiency both under biological and abiotic conditions. Nevertheless, it should be highlighted that the coating of the MNP with carbon still needs to be optimized in order to increase the amount of carbon deposited, the catalytic performance and the stability of the catalysts. On the other hand, impregnated CNT was stable under biological conditions, maintaining mostly of the catalytic performance during the cycles. The efficiency in abiotic reactors has decrease probably due to unavailability of electrons as the material is not regenerated under abiotic conditions.

The high efficiency of the proposed materials, at low concentrations, as redox mediator and the possibility of easily recover with a magnet make these materials preferential as compared with other soluble redox mediators, which need to be continuously added and will be mixed with the treated solution, and also as compared with other insoluble materials to which costly techniques such as filtration need to be applied.

\section{Acknowledgements}

This work was supported by the exploratory EXPL/AAGTEC/0898/2013 financed by the Portuguese Foundation for Science and Technology (FCT). Acknowledges also to FCT under the scope of the strategic funding of UID/BIO/04469/2013 unit and COMPETE 2020 (POCI-01-0145-FEDER-006684) and BioTecNorte operation (NORTE-01-0145-FEDER-000004) funded by European Regional Development Fund under the scope of Norte2020 Programa Operacional Regional do Norte; to the project "AIProcMat@N2020 - Advanced Industrial Processes and Materials for a Sustainable Northern Region of Portugal 2020", with the reference NORTE-01-0145-FEDER-000006, supported by Norte Portugal Regional Operational Programme (NORTE 2020), under the Portugal 2020 Partnership Agreement, through the European Regional Development Fund (ERDF) and to Project POCI-01-0145FEDER-006984-Associate Laboratory LSRE-LCM funded by ERDF through COMPETE2020 - Programa Operacional Competitividade e Internacionalização (POCI) - and by national funds through FCT Fundaça o para a Ciência e a Tecnologia.

Luciana Pereira a post-doc fellowship (SFRH/BPD/110235/2015) from FCT.

\section{Appendix A. Supplementary data}

Supplementary data associated with this article can be found, in the online version, at http://dx.doi.org/10.1016/j.apcatb.2017. 04.060.

\section{References}

[1] C. Pereira, A.M. Pereira, C. Fernandes, M. Rocha, R. Mendes, M.P. Fernández-García, A. Guedes, P.B. Tavares, J.-M. Grenèche, J.P. Araújo, C Freire, Superparamagnetic MFe2O4 ( $\mathrm{M}=\mathrm{Fe}, \mathrm{Co}, \mathrm{Mn})$ nanoparticles: tuning the particle size and magnetic properties through a novel one-step coprecipitation route, Chem. Mater. 24 (8) (2012) 1496-1504

[2] S.K. Das, A.R. Das, A.K. Guha, Gold nanoparticles: microbial synthesis and application in water hygiene management, Langmuir 25 (2009) 8192-8199. 
[3] G.B. Shan, R.Y. Surampalli, R.D. Tyagi, T.C. Zhang, Nanomaterials for environmental burden reduction, waste treatment, and nonpoint source pollution control: a review, Front. Environ. Sci. Eng. China 3 (2009) 249-264

[4] J.L. Figueiredo, M.F.R. Pereira, Carbon as catalyst, in: P. Serp, J.L. Figueiredo (Eds.), Carbon Materials for Catalysis, John Wiley \& Sons, Inc., Hoboken, NJ, 2009, pp. 177-217.

[5] F.P. van der Zee, I.A.E. Bisschops, G. Lettinga, Activated carbon as an electron acceptor and redox mediator during the anaerobic biotransformation of azo dyes, Environ. Sci. Technol. 37 (2003) 402-408.

[6] L. Pereira, R. Pereira, M.F.R. Pereira, F.P. van der Zee, F.J. Cervantes, M.M. Alves, Thermal modification of activated carbon surface chemistry improves its capacity as redox mediator for azo dye reduction, J. Hazard. Mater. 183 (2010) 931-939.

[7] R. Pereira, M.F.R. Pereira, M.M. Alves, L. Pereira, Carbon based materials as novel redox mediators for dye wastewater biodegradation, Appl. Catal. B: Environ. 144 (2014) 713-720.

[8] R. Pereira, A.F. Salvador, P. Dias, M.F.R. Pereira, M.M. Alves, L. Pereira, Perspectives on carbon materials as powerful catalysts in continuous anaerobic bioreactors, Water Res. 101 (2016) 441-447.

[9] G. Mezohegyi, A. Kolodkin, U.I. Castro, C. Bengoa, F. Stuber, J. Font, A. Fabregat, Effective anaerobic decolorization of azo dye acid orange 7 in continuous upflow packed-bed reactor using biological activated carbon system, Ind. Eng. Chem. Res. 46 (2007) 6788-6792.

[10] G. Mezohegyi, C. Bengoa, F. Stuber, J. Font, A. Fabregat, A. Fortuny, Novel bioreactor design for decolourisation of azo dye effluents, Chem. Eng. J. 143 (1-3) (2008) 293-298.

[11] G. Mezohegyi, F. Gonçalves, J.J.M. Órfão, A. Fabregat, A. Fortuny, J. Font, C. Bengoa, F. Stuber, Tailored activated carbons as catalysts in biodegradation of textile azo dyes, Appl. Catal. B: Environ. 94 (2010) 179-185.

[12] H. Fu, D. Zhu, Graphene oxide-facilitated reduction of nitrobenzene in sulfide-containing aqueous solutions, Environ. Sci. Technol. 47 (2013) 4204-4210.

[13] H.J. Amezquita-Garcia, E. Razo-Flores, F.J. Cervantes, J.R. Rangel-Mendez, Activated carbon fibers as redox mediators for the increased reduction of nitroaromatics, Carbon 55 (2013) 276-284.

[14] H.J. Amezquita-Garcia, J.R. Rangel-Mendez, F.J. Cervantes, E. Razo-Flores, Activated carbon fibers with redox-active functionalities improves the continuous anaerobic biotransformation of 4-nitrophenol, Chem. Eng. J. 286 (2016) 208-215.

[15] A. Colunga, J.R. Rangel-Mendez, L.B. Celis, F.J. Cervantes, Graphene oxide as electron shuttle for increased redox conversion of contaminants under methanogenic and sulfate-reducing conditions, Biores. Technol. 175 (2015) 309-314.

[16] L. Pereira, R. Pereira, M.F. Pereira, M.M. Alves, Effect of different carbon materials as electron shuttles in the anaerobic biotransformation of nitroanilines, Biotechnol. Bioeng. 113 (6) (2016) 1194-1202.

[17] L.C.A. Oliveira, R.V.R.A. Rios, J.D. Fabris, V. Garg, K. Sapag, R.M. Lago, Activated carbon/iron oxide magnetic composites for the adsorption of contaminants in water, Carbon 40 (2002) 2177-2183.

[18] L. Ai, H. Huang, Z. Chen, X. Wei, J. Jiang, Activated carbon $/ \mathrm{CoFe}_{2} \mathrm{O}_{4}$ composites: facile synthesis, magnetic performance and their potential application for the removal of malachite green from water, Chem. Eng. J. 156 (2010) 243-249.

[19] C. Pereira, A.M. Pereira, P. Quaresma, P.B. Tavares, E. Pereira, J.P. Araújo, C. Freire, Superparamagnetic $\gamma$-Fe2O3@SiO2 nanoparticles: a novel support for the immobilization of [VO(acac)2], Dalton Trans. 39 (2010) 2842-2854.

[20] J.C. Tristão, A.A.S. Oliveira, J.D. Ardisson, A. Dias, R.M. Lago, Facile preparation of carbon coated magnetic Fe304 particles by a combined reduction/CVD process, Mater. Res. Bull. 46 (5) (2011) 748-754.
[21] X. Shouhu, H. Lingyun, J. Wanquan, G. Xinglong, H. Yuan, C. Zuyao, A facile method to fabricate carbon-encapsulated $\mathrm{Fe}_{3} \mathrm{O}_{4}$ core/shell composites, Nanotechnology 18 (3) (2007) 035602.

[22] A.A.S. Oliveira, J.C. Tristao, J.D. Ardisson, A. Dias, R.M. Lago, Production of nanostructured magnetic composites based on $\mathrm{Fe}(0)$ nuclei coated with carbon nanofibers and nanotubes from red mud waste and ethanol, Appl Catal. B-Environ. 105 (2011) 163-170.

[23] Q. Yang, H. Choi, S.R. Al-Abed, D.D. Dionysiou, Iron-cobalt mixed oxide nanocatalysts: heterogeneous peroxymonosulfate activation, cobalt leaching, and ferromagnetic properties for environmental applications, Appl. Catal. B: Environ. 88 (3) (2009) 462-469.

[24] O.S.G.P. Soares, A.G. Gonçalves, J.J. Delgado, J.J.M. Órfão, M.F.R. Pereira, Modification of carbon nanotubes by ball-milling to be used as ozonation catalysts, Catal. Today 249 (0) (2015) 199-203.

[25] L. Zhang, Y. Wu, Sol-gel synthesized magnetic $\mathrm{MnFe}_{2} \mathrm{O}_{4}$ spinel ferrite nanoparticles as novel catalyst for oxidative degradation of methyl orange, J. Nanomater. (2013) 1-6.

[26] S. Ali, N.A. Mohd Zabidi, D. Subbarao, Correlation between Fischer-Tropsch catalytic activity and composition of catalysts, Chem. Cent. J. 5 (2011), 68-68.

[27] T.P. Braga, D.F. Dias, M.F. de Sousa, J.M. Soares, J.M. Sasaki, Synthesis of air stable FeCo alloy nanocrystallite by proteic sol-gel method using a rotary oven, J. Alloy Compd. 622 (2015) 408-417.

[28] D. Ma, T. Veres, L. Clime, F. Normandin, J. Guan, D. Kingston, B. Simard, Superparamagnetic $\mathrm{Fe}_{\mathrm{x}} \mathrm{O}_{\mathrm{y}} @ \mathrm{SiO}_{2}$ core-shell nanostructures: controlled synthesis and magnetic characterization, J. Phys. Chem. C 111 (5) (2007) 1999-2007.

[29] L. Roldan, S. Armenise, Y. Marco, E. Garcia-Bordeje, Control of nitrogen insertion during the growth of nitrogen-containing carbon nanofibers on cordierite monolith walls, Phys. Chem. Chem. Phys. 14 (10) (2012) 3568-3575.

[30] D. Astruc, F. Lu, J.R. Aranzaes, Nanoparticles as recyclable catalysts: the fast-growing frontier between homogeneous and heterogeneous catalysts, Angew. Chem. Int. Ed. 44 (2005) 7852-7872

[31] L. Pereira, F. Mehboob, A.J. Stams, M.M. Mota, H.H. Rijnaarts, M.M. Alves, Metallic nanoparticles: microbial synthesis and unique properties for biotechnological applications, bioavailability and biotransformation, Crit. Rev. Biotechnol. 35 (1) (2015) 114-128.

[32] C. Lee, D.L. Sedlak, Enhanced formation of oxidants from bimetallic nickel-iron nanoparticles in the presence of oxygen, Environ. Sci. Technol. 42 (22) (2008) 8528-8533.

[33] J.J. Liskowitz, M.J. Liskowitz, S. Chen, 2009. Reactive atomized zero valent iron enriched with sulfur and carbon to enhance corrosivity and reactivity of the iron and provide desirable reduction products. Patent application number: 20090191084. http://www.faqs.org/patents/app/20090191084.

[34] C. Noubactep, The fundamental mechanism of aqueous contaminant removal by metallic iron, Water SA 36 (2010) 663-670.

[35] A.O. Adebiyi, C.A. Togo, T. Mutanda, C. Slatter, C.G. Whiteley, Decolourisation and degradation of reactive blue 2 by sulphate reducing bacteria (SRB) and zero valent iron in a biosulphidogenic reactor, Afr. J. Biotechnol. 10 (2011) 584-588.

[36] Z. Ji, X. Shen, X. Yue, H. Zhou, J. Yang, Y. Wang, L. Ma, K. Chen, Facile synthesis of magnetically separable reduced graphene oxide/magnetite/silver nanocomposites with enhanced catalytic activity, J. Colloid Int. Sci. 459 (2015) 79-85. 